\title{
Penile Intraepithelial Neoplasia
}

National Cancer Institute

\section{Source}

National Cancer Institute. Penile Intraepithelial Neoplasia. NCI Thesaurus. Code C4596.

A precancerous neoplastic lesion that arises from the penis. It is characterized by

dysplastic changes of the squamous epithelium with an intact basement membrane. 